\title{
Life on a planet of its own: regulation of RNA polymerase I transcription in the nucleolus
}

\author{
Ingrid Grummt \\ Division of Molecular Biology of the Cell II, German Cancer Research Center, D-69120 Heidelberg, Germany
}

Mammalian cells contain 100 or more copies of tandemly repeated ribosomal RNA (rRNA) genes per haploid genome. These genes are transcribed with high efficiency to keep up with the cell's metabolic activity and demand for ribosomes. Alterations in cell proliferation are accompanied by profound changes in the transcription rate of rRNA genes. Thus, by responding to changes in the cellular environment, transcription by RNA polymerase I (Pol I) ultimately determines ribosome production and the potential for cell growth and proliferation. There are several comprehensive reviews that discuss regulation of rRNA synthesis in vertebrates and yeast (Grummt 1999; Reeder 1999; Warner 1999; Moss and Stefanovsky 2002). However, new data have been produced even since the latest of these reviews that uncover the mechanisms that link Pol I transcription to cellular physiology. In this review, I restrict the background information to the minimal level that is required for understanding initiation complex formation at the rDNA promoter before proceeding to review the regulatory pathways that adapt cellular rRNA synthesis to cell metabolism and growth.

\section{Structural organization of the rRNA transcription unit}

In higher vertebrates, a standard rDNA transcription unit encodes the precursor to $18 \mathrm{~S}, 28 \mathrm{~S}$, and 5.8S rRNAs. Each unit also contains important sequence elements that regulate pre-rRNA transcription, such as the rDNA promoter, enhancers, spacer promoters, an origin of replication, transcription terminators, and a replication fork barrier that prevents replication forks from colliding with transcribing RNA polymerase I during S phase. The tandem arrangement of multiple rDNA genes may have been useful to increase gene dosage and to maintain the well-recognized rRNA sequence homology. With the exception of closely related species, eukaryotic rDNA promoter sequences have diverged significantly. Consistent

Corresponding author.

E-MAIL I.Grummt@dkfz-heidelberg.de; FAX 49-6221-423404.

Article and publication are at http://www.genesdev.org/cgi/doi/10.1101/ gad.1098503R. with this sequence disparity, rDNA transcription is generally specific to taxonomic orders, the promoter of one group not being recognized by the transcription machinery of others (for review, see Heix and Grummt 1995). With a few exceptions, rDNA promoters share a common modular organization, consisting of a start site proximal core promoter $(\mathrm{CP})$ and an upstream control element (UCE). The stereospecific alignment of both sequence elements is crucial for efficient transcription initiation. Analysis of structural parameters of ribosomal gene promoters from human to lower plants revealed the conservation of specific structural features, rather than base sequence, that are fundamental for promoter function (Marilley and Pasero 1996; Marilley et al. 2002). Apparently, a structural code, in addition to primary sequence, directs specific DNA-protein interactions at the rDNA promoter and may play an important function in transcriptional control.

\section{Basal Pol I transcription initiation factors}

RNA polymerase I is unique in that in most eukaryotes its sole function is the transcription of genes encoding the large rRNAs. Like Pol II and Pol III, it requires auxiliary factors that mediate promoter recognition, promote transcription elongation, and facilitate transcription termination. Briefly, initiation of mammalian rDNA transcription is mediated by a specific multiprotein complex containing Pol I and at least four basal transcription initiation factors (Fig. 1). Preinitiation complex formation requires the synergistic action of the upstream binding factor (UBF; Jantzen et al. 1990) and the promoter selectivity factor, termed TIF-IB in mouse (Clos et al. 1986) and SL1 in humans (Learned et al. 1985). UBF contains several HMG boxes, a motif known to bend DNA. Like other HMG proteins, UBF interacts with the minor groove of DNA and binds to structured nucleic acids such as kinked DNA, cruciforms, or four-way junctions (Putnam et al. 1994). The tandem HMG boxes enable a single dimer of UBF to wrap the DNA in a righthanded direction, forming a loop of almost $360^{\circ}$ once every $140 \mathrm{bp}$, thereby bringing the core and the UCE into close proximity (Bazett-Jones et al. 1994; Copenhaver et 


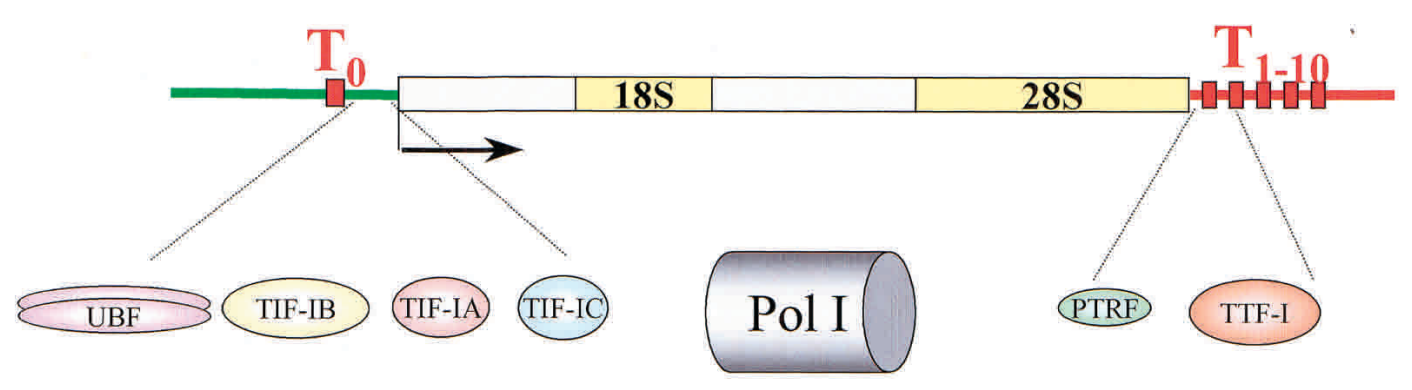

\section{Initiation}

\section{Termination}

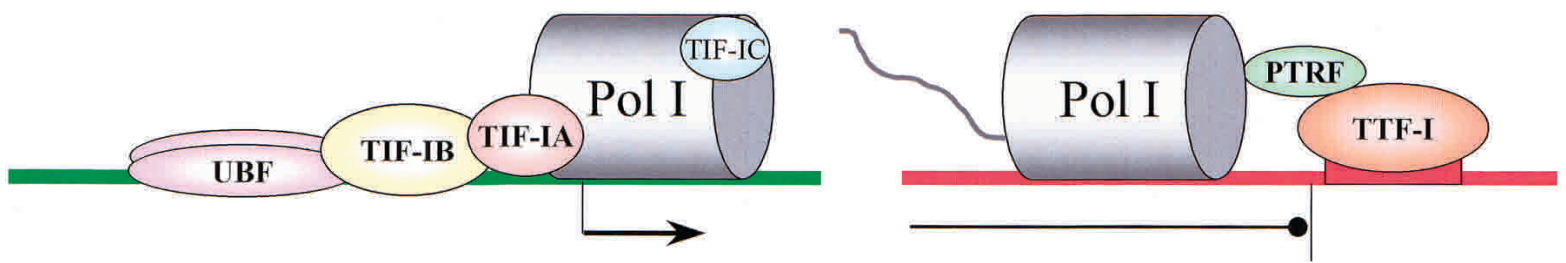

Figure 1. A diagram depicting the structural organization of the murine rDNA transcription unit and the basal factors required for faithful transcription initiation and termination. The green line marks sequences upstream of the transcription start site, including the rDNA promoter and the upstream terminator $T_{0}$. The red line marks sequences downstream of the rRNA coding region, containing the terminator elements $\mathrm{T}_{1-10}$. The cartoon below shows the basal transcription initiation factors (for details, see text), a schematic of the transcription initiation complex, and the two proteins, TTF-I (transcription termination factor) and PTRF (polymerase and transcript release factor) that are required for Pol I transcription termination.

al. 1994). This structure may provide the correct scaffolding for productive interactions between UBF and TIF-IB/SL1 bound to the two promoter elements and facilitate initiation complex formation. UBF is known to activate rDNA transcription by recruiting Pol I to the rDNA promoter, stabilizing binding of TIF-IB/SL1, and competing with nonspecific DNA-binding proteins, such as histone H1 (Kuhn and Grummt 1992; Kuhn et al. 1993). Moreover, UBF has been shown to bind to nucleosomes and displace histone $\mathrm{H} 1$ from the linker region on preassembled nucleosomes (Kermekchiev et al. 1997).

Promoter specificity is conferred by TIF-IB/SL1, a protein complex containing the TATA-binding protein (TBP) and three Pol I-specific TBP-associated factors $\mathrm{TAF}_{\mathrm{I}} 48, \mathrm{TAF}_{\mathrm{I}} 68, \mathrm{TAF}_{\mathrm{I}} 95 / 110$ (Comai et al. 1992; Eberhard et al. 1993; Heix et al. 1997). In contrast to TFIID, the factor that nucleates Pol II transcription initiation complexes, the TBP subunit of TIF-IB/SL1 does not bind to DNA, and promoter recognition is carried out by the associated $\mathrm{TAF}_{\mathrm{I}} \mathrm{s}$. As is discussed below, the most important step in the assembly of a productive transcription initiation complex is the recruitment of Pol I to the rDNA promoter. This is achieved by interaction of UBF with PAF53, the mammalian homolog of the yeast Pol I subunit A49 (Hanada et al. 1996; Seither et al. 1997), and by interaction of TIF-IB/SL1 with TIF-IA. TIF-IA is the mammalian homolog of yeast Rrn3p (Bodem et al. 2000; Moorefield et al. 2000), a regulatory factor that is asso- ciated with the initiation-competent subpopulation of Pol I (Miller et al. 2001; Yuan et al. 2002).

In Saccharomyces cerevisiae, rDNA transcription requires Pol I, the TATA-binding protein (TBP), Rrn3p, the core factor $(\mathrm{CF})$, and the upstream activating factor (UAF). CF is composed of three stably associated proteins encoded by $R R N 6, R R N 7$, and $R R N 11$. UAF is a complex of six polypeptides including Rrn5p, Rrn9p, Rrn10p, the two histones $\mathrm{H} 3$ and $\mathrm{H} 4$, and Uaf30p (see Fig. 2; for review, see Nomura 2001). Binding of UAF to the promoter is necessary to recruit $\mathrm{CF}$ and the Pol I-Rrn3p complex. Transcription experiments with immobilized templates revealed that CF and TBP, along with Pol I and Rrn3p, are released from the template upon transcription, whereas UAF remains associated with the upstream promoter element, presumably serving as a scaffold for reinitiation (Aprikian et al. 2001). These findings support a model in which essential components of the Pol I machinery cycle on and off the promoter with each round of transcription. In contrast, similar experiments with human Pol I and the respective factors demonstrated recycling of Pol I and TIF-IA/ Rrn3p, but not of UBF and TIF-IB/SL1 (Panov et al. 2001).

\section{The RNA polymerase I holoenzyme concept}

The model of a stepwise preinitiation complex (PIC) formation at the rDNA promoter is now being reconsidered 

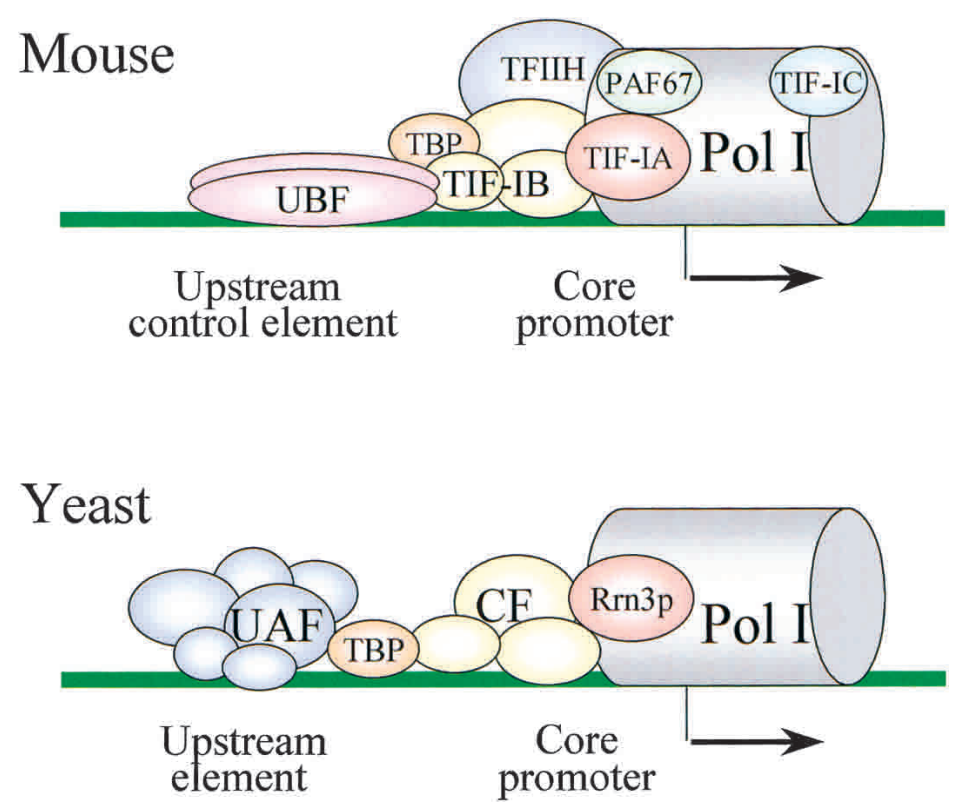

Figure 2. A cartoon view of the basal components of the murine and yeast Pol I transcription initiation complexes. The green line marks rDNA promoter sequences, the bent arrow indicates the transcription initiation site, and the shaded objects represent proteins that are involved in preinitiation complex formation. TIF-IB is composed of four subunits; for example, TBP and three TBP-associated factors, $\operatorname{TAF}_{\mathrm{I}} 95, \mathrm{TAF}_{\mathrm{I}} 68$, and $\mathrm{TAF}_{\mathrm{I}} 48$ (yellow). UAF consists of Rrn5p, Rrn9p, Rrn10p, histones $\mathrm{H} 3$ and H4, and Uaf30p (blue), whereas CF consists of Rrn6p, Rrn7p, and Rrn11p (yellow). Rrn3p is the yeast homolog of mammalian TIF-IA. PAF67 is a $67-\mathrm{kD}$ Pol I-associated factor that, like TIFIA, decorates the initiation-competent subpopulation of Pol I (Pol I $\beta$ ). in view of reports of Pol I "holoenzymes." In plants, mammals, and frogs, large Pol I-containing protein machineries have been identified that contain most, if not all, factors required for transcription initiation and combine several enzymatic entities (Saez-Vasquez and Pikaard 1997; Seither et al. 1998; Albert et al. 1999; Hannan et al. 1999). Although the composition of these large protein complexes is not well defined, they all contain Pol I and basal transcription factors to support rDNA transcription in vitro and additional polypeptides that play a role in protein phosphorylation (CKII), chromatin modification (PCAF), or DNA repair/replication (topoisomerase I, Ku70/80, and PCNA). Interestingly, TFIIH, the protein complex that plays an essential role in transcription of protein-coding genes and nucleotide excision repair, was also found to be an integral part of the Pol I holoenzyme (Iben et al. 2002). These findings are compatible with a mechanism by which Pol I is recruited to the rDNA promoter as a giant multiprotein complex that contains proteins required for rRNA synthesis and maturation, chromatin modification, and DNA repair. In support of this view, a novel ribonucleoprotein complex enriched in nucleolar proteins has been purified from yeast that contained Pol I, TBP, Rrn3p, Rrn5p, Rrn7p, and Reb1p along with rRNA-processing factors like Noplp, Cbf5p, Nhp2p, and Rrp5p as well as small nucleolar RNAs (Fath et al. 2000). The ribonucleoprotein complex supports accurate transcription, termination, and pseudouridylation of rRNA, suggesting that it represents a nucleolar subdomain that serves as a scaffold for coordinated rRNA synthesis and processing. However, it cannot be excluded that after breakage of the cells, such complexes are artificially generated by specific or nonspecific macromolecular interactions. In support of this, recent FRAP experiments have demonstrated that Pol I subunits enter the nucleolus as distinct subunits rather than as a preassembled complex. These observations suggest that assembly of Pol I and functional initiation complexes may proceed in a sequential manner via metastable intermediates, each with increasing stability as more subunits are added (Dundr et al. 2002).

\section{Dynamics of the Pol I transcription apparatus}

The classical view of transcription initiation complex formation is that of an ordered stepwise assembly of multiple proteins on the promoter via specific proteinprotein interactions or, alternatively, binding of a preassembled ready-to-use multiprotein complex, often termed a "factory." Indeed, the nucleolus can be regarded as the archetype of such a transcription factory because it represents a stable, architectural framework within which most steps of ribosome biosynthesis, that is, rRNA transcription, processing, maturation, and ribosome assembly, take place in a spatial and temporal order. The view of the nucleolus as a highly organized environment has been eclipsed by recent findings that monitored the movement of individual subunits of Pol I and basal factors, such as UBF, $\mathrm{TAF}_{\mathrm{I}} 48$, and TIF-IA, in mammalian nucleoli (Dundr et al. 2002). Using green fluorescent protein (GFP) tags that permit the observation of proteins in living cells by the FRAP (fluorescent recovery after photobleaching) technique, the kinetics of assembly and elongation of mammalian Pol I has been analyzed. The data revealed that the Pol I transcription machinery is a highly dynamic complex that assembles in a stochastic fashion from freely diffusible subunits. Each of the components is steadily and rapidly exchanged between the nucleoplasm and the nucleolus. Real-time evaluation of promoter-associated multiprotein complexes revealed occupancy of only a few seconds, indicating that the association of transcription factors with their binding sites is transient. A hit-and-run mechanism was proposed, in which transcriptional fac- 
tors quickly exchange between individual rDNA promoters. Pol I subunits have been found to enter the nucleolus as distinct subunits rather than as a preassembled holoenzyme. Surprisingly, Pol I appears to break apart after transcription termination and needs to reassemble before transcription initiation. Calculations of the FRAP data indicate that transcription initiation at a ribosomal promoter occurs every $\sim 1.4 \mathrm{sec}$, Pol I subunits reside in the pool for $\sim 9$ to $\sim 37 \mathrm{sec}$, and the residence time of elongating Pol $\mathrm{I}$ is $2-3 \mathrm{~min}$. With the use of computational modeling of imaging data, the in vivo elongation time of Pol I has been determined as $\sim 140 \mathrm{sec}$, corresponding to an elongation rate of $95 \mathrm{nt} / \mathrm{sec}$ for a human rDNA gene of $13.3 \mathrm{~kb}$. Although one can question whether imaging and mathematical models can provide such an unambiguous picture of assembly, the estimated numbers are approximately the same as those obtained by French et al. (2003), who calculated the elongation rate of yeast Pol I directly from the number of Pol I molecules per rRNA gene and the rate of rRNA synthesis.

\section{Mechanisms regulating Pol I transcription}

Transcription of rRNA genes is highly regulated to be responsive to both general metabolism and specific environmental challenges (for review, see Grummt 1999). Changes in Pol I transcription regulate ribosome production and thus determine the potential for cell proliferation. rDNA genes are present in multiple copies, and therefore, rRNA synthesis could be modulated by varying the transcription rate per gene or by varying the number of active genes. Although there are several reports demonstrating that in yeast both of these mechanisms may operate under certain conditions (for review, see Reeder 1999), a recent electron microscopy study revealed that the overall initiation rate, and not the number of active genes, determines the rate of rDNA transcription during exponential growth in yeast (French et al. 2003). Similarly, in vertebrates the level of cellular rRNA is regulated by changing the rate of transcription initiation at active rDNA genes rather than by activating silent transcription units. In vivo psoralen-cross-linking studies that can distinguish between transcriptionally active and inactive genes have revealed that even in exponentially growing mammalian cells that synthesize high levels of pre-rRNA, only half of the rDNA genes are transcriptionally active and maintained in an "open" chromatin conformation. The other half that corresponds to inactive gene copies resides in a compact, nucleosomal structure. The ratio of active and inactive rRNA genes is stably propagated through the cell cycle and is independent of the cellular rRNA synthetic activity (Conconi et al. 1989). The present view is that growth-dependent modulation of Pol I transcription occurs at transcriptionally competent gene copies, and "opening" or "closing" of ribosomal genes is not involved in short-term Pol I transcription regulation. Epigenetic mechanisms that mediate rDNA silencing will be discussed in another review (Grummt and Pikaard 2003).

Early studies in mice and rats have demonstrated upor down-regulation of rRNA synthesis after partial hepatectomy, hormone administration, cycloheximide treatment, or nutrient starvation (for reviews, see Jacob 1995; Grummt 1999). Deprivation of a single amino acid from the culture medium has been demonstrated to cause a rapid shut-off of nucleolar transcription (Grummt et al. 1976). Meanwhile, several studies have been published that address the mechanisms underlying cell-cycle- and growth-factor-dependent fluctuations of Pol I activity. Indeed, almost any perturbation that slows down cell growth or protein synthesis decreases rDNA transcription. Evidence accumulated to date indicates that almost any of the proteins required for Pol I transcription can serve as a target for regulatory pathways. For example, changes in the phosphorylation pattern of UBF play a key role in modulating rDNA activity during cell cycle progression. UBF is phosphorylated at multiple sites, and phosphorylation of the $\mathrm{C}$ terminus by casein kinase II facilitates the interaction between UBF and TIF-IB/SL1 (Tuan et al. 1999). In quiescent cells, UBF is hypophosphorylated and transcriptionally inactive (O'Mahony et al. 1992; Voit et al. 1992, 1995). Moreover, interactions with $\mathrm{pRb}, \mathrm{p} 130$, and $\mathrm{p} 53$ have been shown to impair UBF functions, such as DNA binding or the interaction with TIF-IB/SL1 /Cavanaugh et al. 1995; Voit et al. 1997; Budde and Grummt 1999; Zhai and Comai 2000; Ciarmatori et al. 2001). Finally, acetylation of UBF by the histone acetyltransferase CBP has been reported to enhance UBF activity in vitro, and overexpression of both CBP and p300 enhances Pol I activity in vivo (HirschlerLankiewicz et al. 2001). Besides UBF, the TAF 68 subunit of TIF-IB/SL1 is acetylated by PCAF. Acetylation enhances binding of $\mathrm{TAF}_{\mathrm{I}} 68$ to rDNA and augments Pol I transcription. Conversely, deacetylation of $\mathrm{TAF}_{\mathrm{I}} 68$ by the $\mathrm{NAD}^{+}$-dependent histone deacetylase mSir2a represses Pol I transcription (Muth et al. 2001). As is discussed below, there is evidence for changes in the phosphorylation pattern of SL1 (Heix et al. 1998), UBF (Klein and Grummt 1999; Voit et al. 1999), and TTF-I (Sirri et al. 2000, 2002) that correlate with cell-cycle-specific fluctuations of rDNA transcription. Thus, reversible acetylation and phosphorylation of basal components of the Pol I transcription machinery may be an effective means to regulate rDNA transcription.

\section{Growth-dependent transcription regulation by TIF-IA}

Conditions that harm cellular metabolism, that is, nutrient starvation, toxic lesion, aging, cancer, and viral infections, down-regulate rDNA transcription. Conversely, rDNA transcription is up-regulated upon reversal of such conditions and by agents that stimulate growth. This growth-dependent regulation of rRNA synthesis is evolutionarily conserved and has been observed in bacteria, yeast, plants, and vertebrates. The key player in growth-dependent regulation of rDNA transcription is the transcription initiation factor TIF-IA, the mamma- 
lian homolog of yeast Rrn3p (Buttgereit et al. 1985; Schnapp et al. 1993; Bodem et al. 2000; Moorefield et al. 2000). A preinitiation complex containing Pol I can be formed in the absence of TIF-IA/Rrn3p; however, formation of the first phosphodiester bond requires the presence of TIF-IA/Rrn3p (Schnapp and Grummt 1991; Schnapp et al. 1993). Following initiation, TIF-IA is released from the ternary complex and can associate with another preinitiation complex. The activity of TIF-IA/ Rrn3p is regulated by diverse extracellular signals, suggesting that this factor adapts Pol I transcription to cell growth. In both mammals and yeast, a large fraction of Pol I, the "bulk" enzyme, termed Pol $\mathrm{I} \alpha$, is unable to support specific initiation, despite its ability to synthesize RNA from nonspecific templates (Tower and Sollner-Webb 1987; Schnapp et al. 1990; Miller et al. 2001). Only the fraction of Pol I ( $\mathrm{Pol} \mathrm{I} \beta$ ) that is associated with TIF-IA/Rrn3p is capable of assembling into a productive initiation complex (Yamamoto et al. 1996; Milkereit and Tschochner 1998), suggesting that TIF-IA/Rrn3p bridges Pol I to the preinitiation complex. Importantly, the amount of TIF-IA/Rrn3p associated with Pol I, but not the overall level of TIF-IA/Rrn3p, is decreased in growtharrested cells, indicating that transcriptional shut-off is caused by dissociation of the Pol I/Rrn3p complex (Milkereit and Tschochner 1998; Cavanaugh et al. 2002; Yuan et al. 2002). These and other experiments demonstrate that most, if not all, growth-dependent control of rDNA transcription may be exerted by the formation and recruitment of TIF-IA/Rrn3p-Pol I complexes to the rDNA promoter. This suggests a regulatory cycle in which TIFIA/Rrn3p dissociates from Pol I during initiation or after promoter escape, is inactivated after release, and must be reactivated before association with another polymerase and assembly into a new preinitiation complex (Aprikian et al. 2001).

The role of TIF-IA/Rrn $3 p$ as a bridge between Pol I and TIF-IB/SL1 or CF, respectively, has been supported by genetic and biochemical experiments in S. cerevisiae and mammals demonstrating that TIF-IA/Rrn3p interacts with RPA43, a unique subunit of Pol I (Peyroche et al. 2000; Fath et al. 2001; Cavanaugh et al. 2002; Yuan et al. 2002). In addition, TIF-IA has been found to interact with PAF67, a 67-kD Pol I-associated factor that decorates the initiation-competent form of Pol I (Seither et al. 2001). This suggests that by interacting with PAF67, TIF-IA may target a functional subset of Pol I molecules into a productive transcription initiation complex. TIF-IA also interacts with two $\mathrm{TAF}_{\mathrm{I}}$ subunits of TIF-IB/SL1 (Miller et al. 2001; Yuan et al. 2002) and the Rrn6p subunit of CF (Peyroche et al. 2000). Thus, by associating with both Pol I and the promoter selectivity factor, TIF-IA may link both protein complexes.

Given the essential role for TIF-IA/Rrn3p in targeting Pol I to promoter-bound TIF-IB/SL1, the interactions with $\mathrm{TAF}_{\mathrm{I}} \mathrm{S}$, RPA43, and PAF67 are expected to be major targets of regulatory pathways that control the assembly of Pol I preinitiation complexes. Indeed, interactions between TIF-IA/Rrn3p with Pol I are affected by diverse regulatory pathways that link the cell's biosynthetic ac- tivities to environmental conditions. Nutrient starvation, density arrest, and protein synthesis inhibitors lead to inactivation of TIF-IA (Cavanaugh et al. 2002; Yuan et al. 2002). TIF-IA is phosphorylated at multiple sites, and signals that affect cell metabolism alter the phosphorylation pattern of TIF-IA (Zhao et al. 2003). In densityarrested, cycloheximide-treated, and amino-acid-starved cells, TIF-IA is hypophosphorylated and incapable of binding to Pol I (Yuan et al. 2002). Thus, cellular signaling cascades directly target TIF-IA, and reversible phosphorylation regulates the association of TIF-IA with Pol I and hence transcription initiation complex formation.

\section{TOR and MAP kinase signaling pathways target TIF-IA}

We are just beginning to understand some of the complex pathways the cell uses to gauge external growth signals and coordinate regulatory inputs to modulate Pol I activity. It is well established that starvation or lack of nutrients impairs ribosome and protein synthesis, the major energy-consuming processes of the cell. An important finding is that the target of rapamycin (TOR)/p70 S6 kinase $\left(\mathrm{p} 70^{\mathrm{S} 6 \mathrm{k}}\right)$ pathway senses the availability of nutrients and regulates both rRNA and protein synthesis (for review, see Proud 2002). The TOR/p70 ${ }^{\text {S6k }}$ pathway controls translation, ribosome biogenesis, and many growthrelated processes in response to nutrients and environmental conditions. Nutrient deprivation inhibits mTOR kinase activity and blocks cell growth. The mechanism by which TOR senses nutrient availability is unknown, as is its involvement in regulation of rDNA transcription. Extracts from cells treated with the mTOR inhibitor rapamycin are transcriptionally inactive (Mahajan 1994; Zaragoza et al. 1998), and treatment of yeast cells with rapamycin leads to inhibition of rRNA synthesis (Powers and Walter 1999). Interestingly, transcriptional activity of rapamycin-treated cell extracts can be restored by mTOR, p70 $56 \mathrm{k}$, or recombinant TIF-IA (I. Grummt, unpubl.). This suggests that phosphorylation by $\mathrm{mTOR}, \mathrm{p} 70^{\mathrm{s} 6 \mathrm{k}}$, or downstream kinase(s) is required for TIF-IA activity. In support of this, the assembly of TIF-IA/Pol I complexes has been found to be impaired in rapamycin-treated cells. Thus, $\mathrm{TOR} / \mathrm{p} 70^{\mathrm{S} 6 \mathrm{k}}$ signaling regulates rDNA transcription by modulating the activity of TIF-IA.

A different pathway, but similar scenario, mediates transcriptional activation by growth factors. After mitogenic stimulation of quiescent cells, a transient 10 -fold increase in pre-rRNA synthesis was observed (Zhao et al. 2003). The rapid response of rDNA transcription to growth factors was blocked by PD98059, an inhibitor of MEK1/2, indicating that Pol I transcription is up-regulated by activation of the Ras-ERK pathway. Transcriptional activation correlates with phosphorylation of TIFIA at two specific serine residues (S633 and S649) by ERK and RSK kinases. Phosphorylation at these serine residues activates TIF-IA and increases cellular pre-rRNA synthesis. Replacement of Ser 649 by alanine, on the other hand, abolishes TIF-IA activity, impairs Pol I transcription in vivo and in vitro, and retards cell growth. 
Thus, growth factors regulate rRNA synthesis and nucleolar activity by ERK/RSK-mediated phosphorylation of TIF-IA (Fig. 3). These results underscore the molecular cross-talk between the p $70^{\mathrm{s} 6 \mathrm{k}}$ and ERK signaling pathways (Wang et al. 2001) and demonstrate that TIF-IA is a common final target for growth factor-dependent activation of ribosome biogenesis.

One additional point is worth mentioning. TIF-IA contains a conserved sequence motif, known as the Walker type A or P-loop motif. The P-loop is a flexible glycinerich sequence that is embedded in a well-defined tertiary structure and has been implicated in ATP and GTP binding (Walker et al. 1982). The presence of a potential ATPand GTP-binding site in TIF-IA is interesting, because rRNA synthesis in mouse cells has been shown to be regulated by the intracellular pool sizes of ATP and GTP (Grummt and Grummt 1976). Moreover, recent studies in Escherichia coli have demonstrated that the concentration of initiating nucleoside triphosphates, that is, ATP or GTP, regulate rRNA transcription in a growthrate-dependent manner (Gaal et al. 1997). This suggests that NTP-sensing by rrn P1 promoters links cellular rRNA synthesis to the level of translation and the available energy resources (Schneider et al. 2002). It is tempting to speculate that eukaryotes use a similar ATP/GTPsensing mechanism to integrate extracellular signals into growth-rate-dependent regulation of rRNA synthesis. Alternatively, the pool sizes of ATP and GTP could regulate TIF-IA activity indirectly as a consequence of an effect on mTOR signaling. mTOR itself has been shown to function as an ATP sensor, and mTOR signaling is controlled by intracellular ATP concentrations (Dennis et al. 2001). This finding, together with the role of mTOR signaling in the regulation of TIF-IA activity, may provide a link between nutrient availability, cellular ATP levels, and regulation of rRNA synthesis.

\section{TFIIH and CSB link Pol I transcription to DNA repair}

A dedicated network of DNA repair mechanisms and cell cycle checkpoints safeguards DNA integrity to prevent the deleterious consequences of mutations that lead to cancer and aging. One of these DNA repair pathways, nucleotide excision repair (NER), removes a broad range of helix-distorting injuries, for example, UV-light-induced pyrimidine dimers and bulky chemical adducts. The multistep NER process requires the coordinated action of at least 25-30 polypeptides. It is becoming increasingly evident that NER and transcription are tightly linked by the basal Pol II transcription factor TFIIH. Mutations within the XPB and XPD helicase subunits of TFIIH give rise to genetic disorders such as xeroderma pigmentosum, Cockayne's syndrome, and trichothiodystrophy (Lehmann 2001).

The most striking feature of TFIIH is its multifunctionality. TFIIH is engaged in promoter opening and
Figure 3. A model for activation of Pol I transcription by MAPK signaling pathways. The response of cells to growth factors and other mitogens is mediated by specific receptors including protein tyrosine kinase- and G protein-coupled receptors (R). In response to stimulation, the receptors are activated and initiate signaling events leading to various cellular responses. One such pathway activates the core unit of the MAPK cascade, composed of Raf, MEK1/2, and ERK1/2. Once activated, ERK1/2 phosphorylates and activates $90-\mathrm{kD}$ ribosomal S6 kinase (RSK). After translocation to the nucleus, RSK phosphorylates TIF-IA at Ser 649. Subsequently, ERK1/2 phosphorylates TIF-IA at Ser 633. Phosphorylation at these serine residues is required for interaction with Pol I and transcription complex formation.

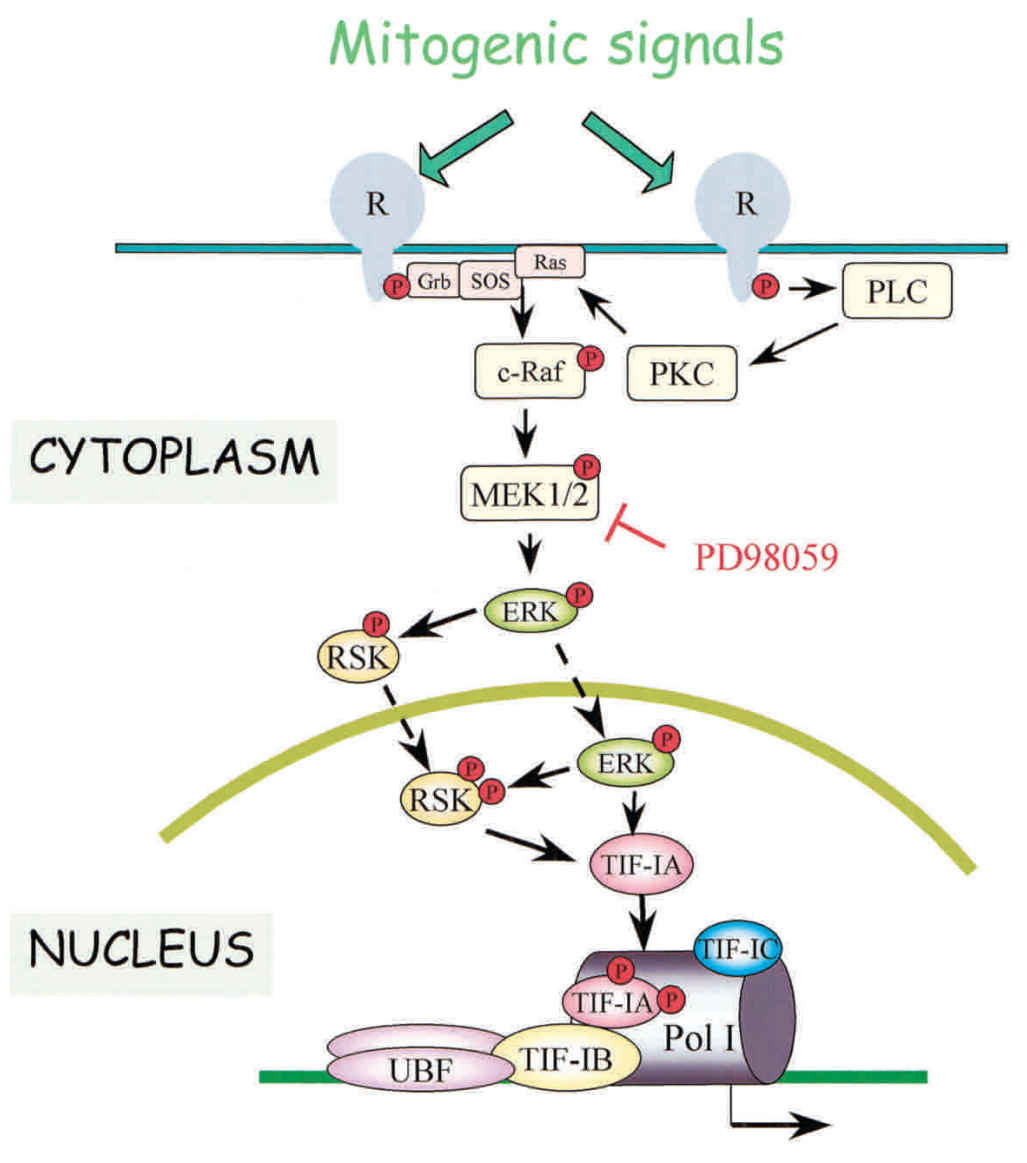


phosphorylation of the C-terminal domain of Pol II in the context of mRNA transcription and DNA opening in the setting of nucleotide excision and transcriptioncoupled repair. In addition, TFIIH serves an essential role in Pol I transcription. GFP-tagged TFIIH is homogenously distributed through the nucleoplasm, with disperse clusters colocalizing with Pol I in nucleoli (Hoogstraten et al. 2002). Electron microscopy and immunogold labeling have shown enrichment of TFIIH at the dense fibrillar component of nucleoli, that is, sites of active rDNA transcription (Iben et al. 2002). Microinjection of antibodies against subunits of TFIIH induced a strong, rapid reduction of rRNA synthesis, demonstrating the requirement of TFIIH in rDNA transcription. In yeast strains carrying temperature-sensitive mutations in Tfb1 and Kin28, the homologs of mammalian p62 and Cdk7, pre-rRNA synthesis declines at a similar rate as in Pol I mutants upon shift to the restrictive temperature. Moreover, biochemical studies have revealed that TFIIH is associated with a subpopulation of TIF-IB/SL1 as well as with the initiation-competent form of Pol I ( $\mathrm{Pol} I \beta$ ). Reconstituted transcription systems lacking TFIIH are transcriptionally inactive, and transcriptional activity can be restored by purified TFIIH (Iben et al. 2002). TFIIH is required for productive but not abortive rDNA transcription, implying a role in transcription elongation. These findings suggest that errors in the DNA template encountered during transcription might be corrected by TFIIH-mediated processes. Noteworthy, recent in vivo photobleaching studies have revealed that TFIIH moves freely and is capable of rapid switching between Pol I, Pol II, and NER complexes with an average residence time of $\sim 25 \mathrm{sec}, \sim 6 \mathrm{sec}$, and $\sim 4 \mathrm{~min}$, respectively (Hoogstraten et al. 2002). Thus, a stochastic exchange of TFIIH occurs between different multiprotein complexes involved in different DNA transactions.

The close interrelationship between DNA repair and rRNA synthesis has further been documented by the finding that CSB, a protein that is defective in Cockayne's syndrome (CS), is required for Pol I transcription. CSB is localized at sites of rDNA transcription and restores rRNA synthesis when transfected in CSB-deficient cells. CSB is part of a megadalton-size protein complex that contains Pol I, TFIIH, and basal Pol I transcription initiation factors and promotes efficient rRNA synthesis in vitro (Bradsher et al. 2002). Mutations in $C S B$, as well as $X P B$ and $X P D$ genes, all of which confer Cockayne's syndrome, disturb the Pol I/TFIIH/CSB complex and reduce rRNA synthesis in vivo. The fragility of this complex could be the molecular basis for some of the clinical features that are associated with the CS phenotype.

\section{Regulation of Pol I transcription during the cell cycle}

Coordination between cell growth and division is a requisite feature of cell proliferation, and unexpected links between nucleolar proteins and the machinery that regulates the cell cycle have been uncovered. In yeast, no significant cell cycle-dependent fluctuations of Pol I transcription have been observed (Elliot and McLaughlin 1979|. In mammalian cells, on the other hand, rDNA transcription strongly oscillates during cell cycle progression. Transcription is maximal in the S and G2 phases, shuts down in mitosis, and slowly recovers in G1. Mitotic silencing of human Pol I transcription is caused by phosphorylation of the $\mathrm{TAF}_{\mathrm{I}} 110$ subunit of SL1 by cdk1/cyclin B at Thr 852 (Heix et al. 1998; Kuhn et al. 1998). As a consequence of this specific phosphorylation, the capability of TIF-IB/SL1 to interact with UBF is impaired, and Pol I transcription is repressed. Moreover, UBF is inactivated during mitosis, presumably both by loss of essential phosphorylations and mitosis-specific inhibitory phosphorylation(s) (I. Grummt, unpubl.). Thus, reversible phosphorylation of TIF-IB/SL1 and UBF is used as a molecular switch to shut down rDNA transcription during mitosis. The mechanisms that trigger reactivation of transcription at the end of mitosis are unknown. Conceivably, cellular phosphatases have to reverse cdk1/cyclin B-mediated phosphorylations to recover TIF-IB/SL1 activity during telophase. A candidate enzyme for reactivation of the Pol I transcription machinery could be Cdc14B, a phosphatase that is sequestered in an inactive state in the nucleolus for most of the cell cycle and is released into the nucleus and cytoplasm at the exit from mitosis (Mailand et al. 2002).

In early G1 phase, rDNA transcription remains low although the activity of TIF-IB/SL1 has been fully restored. The key player for activation of Pol I transcription during G1 progression is UBF. To achieve high levels of rRNA synthetic activity, UBF has to be phosphorylated at two serine residues by G1-specific protein kinases. Cdk4/cyclin D1 targets Ser 484 (Voit et al. 1999), and cdk 2/cyclin E\&A phosphorylates Ser 388 (Voit and Grummt 2001). Mutations that prevent phosphorylation of Ser 388 impair the ability of UBF to associate with Pol I and abrogate transcription. The finding that specific cdk/cyclin complexes modulate the activity of TIF-IB/SL1 and UBF in a cell-cycle-dependent manner links the control of cell cycle progression to regulation of Pol I transcription (Fig. 4).

Another link between cell cycle regulation and rDNA transcription has recently been uncovered by the finding that TAF1, the largest subunit of the Pol II-specific TFIID complex, binds to UBF (Lin et al. 2002). TAF1 (also known as CCG1) has been implicated in the regulation of G1-to-S-phase progression (Hisatake et al. 1993; Ruppert et al. 1993). Interaction of TAF1 with UBF stimulates human rDNA transcription in vivo and in vitro. The results suggest that TAF1 may be specifically engaged in the regulation of genes, including the ribosomal genes, that play a critical role in the coordinate control of cell growth and division.

\section{The nucleolar RENT complex}

Recent studies in yeast point to an important role of the nucleolus in the senescence of eukaryotic cells. Ribosomal RNA genes are located at the AGE locus and some nucleolar functions are impaired in old yeast cells (Gotta 
A

Figure 4. Regulation of Pol I transcription during the cell cycle. (A) Cell-cycledependent fluctuations of pre-rRNA synthesis. FT210 cells, a murine mammary tumor cell line carrying a temperaturesensitive mutant of cdc2 (Yasuda et al. 1991), were synchronized in G2 by culturing at $39^{\circ} \mathrm{C}$ and released from the G2 block by shifting to the permissive temperature $\left(33^{\circ} \mathrm{C}\right)$. At the indicated times, cells were subjected to FACS analysis and nascent RNA was extracted, dotted onto a membrane, and hybridized to a labeled rDNA probe (Klein and Grummt 1999). The rDNA transcription levels differ by about two orders of magnitude in G2- and $\mathrm{M}$ phase cells. (B) Regulation of TIF-IB/SL1 and UBF activity during $M$ and G1 phases. The activity of both TIF-IB/SL1 and UBF is regulated, at least in part, by phosphorylation. At the entry of mitosis, phosphorylation by cdk1/cyclin B inactivates TIF-IB/ SL1 and UBF. After mitotic exit, transcriptional activity remains low despite the fact that TIF-IB/SL1 activity has recovered. UBF is activated during G1 progression by phosphorylation of S484 by cdk4/ cyclin D and S388 by cdk2/cyclin E and A.
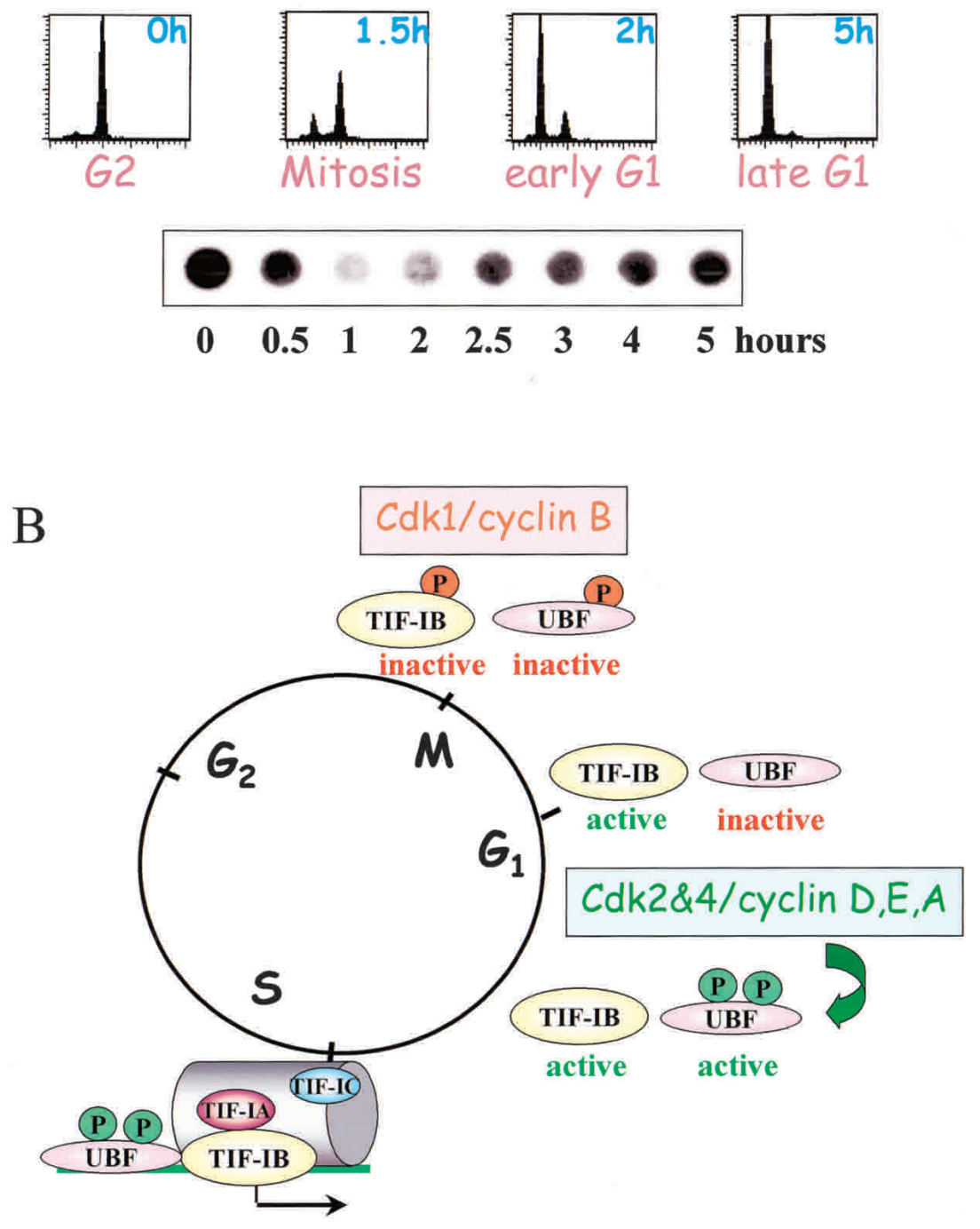

et al. 1997). Transcription of RNA polymerase II genes integrated within the rDNA array is repressed, and this repression is dependent on both UAF (Vu et al. 1999) and Sir2 (silent information regulator \#2), a protein that is conserved from archaea to metazoa. The repressive chromatin structure associated with rDNA silencing also functions in suppressing recombination among rDNA repeats, increasing rDNA stability and extending the yeast life span (Gottlieb and Esposito 1989). Mutations that inactivate Sir2 shorten the yeast life span, and overexpression of Sir2 extends it (Kaeberlein et al. 1999). Sir2 has been shown to be an $\mathrm{NAD}^{+}$-dependent histone deacetylase (Imai et al. 2000), implying that Sir2-induced transcriptional silencing is brought about by deacetylation of either histones or components of the transcription apparatus.

In budding yeast, Sir2 executes functions in rDNA transcription as a component of a nucleolar complex designated RENT (regulator of nucleolar silencing and telophase exit), consisting of at least three proteins, Sir2,
Net1, and Cdc14. Net1, the core subunit of the RENT complex, localizes Sir2 to rDNA and is required for silencing (for review, see Guarente 2000). Net1 physically interacts with Pol I in vitro and stimulates rRNA synthesis (Shou et al. 2001). Net1 and Sir2 cross-link throughout individual rDNA repeats, and recent data demonstrate that the Net1/Sir2 complex spreads unidirectionally downstream of an active rDNA transcription unit (Buck et al. 2002). Silencing requires transcription by Pol I, and the direction of spreading is controlled by the direction of Pol I transcription. To reconcile these findings, a model has been proposed in which the interaction of Net1 with Pol I recruits Sir2 to active rDNA repeats for histone deacetylation, and the unidirectional spreading of RENT/Sir2 is mediated by its association with Pol I.

Besides its role in rDNA silencing, Net1 regulates both the exit from mitosis and the activity of Cdc14, the third component of RENT (Shou et al. 1999). The Cdc14 phosphatase is sequestered in an inactive state in the nucleo- 
lus and is released from the RENT complex at the end of anaphase. Thus, destabilization of the RENT complex appears to be a critical step in provoking exit from mitosis and triggering cell cycle progression. It remains to be investigated whether higher eukaryotes use a complex similar to RENT that links nuclear integrity, transcriptional silencing, and cell cycle control.

\section{Repression of rDNA transcription}

\section{by the tumor suppressor proteins $\mathrm{pRb}$ and $\mathrm{p} 53$}

Tumor suppressor proteins are common targets for genetic alteration in human cancers and have been implicated as key mediators for suppression of cell transformation (for review, see Levine 1997). The related "pocket" proteins $\mathrm{pRb}, \mathrm{p} 107$, and p130 restrict cellular proliferation and have been implicated in cell cycle regulation. The view that $\mathrm{pRb}$ restrains cell proliferation by inactivating factors that are needed for the transcription of genes required for DNA synthesis and cell proliferation was challenged by the discovery that $\mathrm{pRb}$ also represses Pol I transcription. UBF is the target for $\mathrm{pRb}$ induced repression of Pol I transcription. $\mathrm{pRb}$ accumulates in the nucleoli of differentiated or cell-cycle-arrested cells and has been shown to repress rDNA transcription in vitro and in vivo (Cavanaugh et al. 1995; Voit et al. 1997; Hannan et al. 2000). Transcriptional repression is brought about by interaction of the C-terminal part of $\mathrm{pRb}$ with HMG boxes 1 and 2 of UBF. Thus, inactivation of UBF appears to be a most effective way for $\mathrm{pRb}$ to shut down rRNA synthesis and inhibit cell growth. The acetyltransferase CBP that activates Pol I transcription by acetylating UBF competes with $\mathrm{pRb}$ for binding to UBF, suggesting that the competitive recruitment of CBP and $\mathrm{pRb}$ regulates UBF acetylation and rDNA transcription (Pelletier et al. 2000). Interestingly, rRNA synthesis was unaffected in $\mathrm{Rb}^{-/-}$cells, whereas Pol I transcription was elevated in cells lacking either all three pocket proteins or $\mathrm{pRb}$ and $\mathrm{p} 130$. This suggests overlapping functions of the $\mathrm{pRb}$ family members in the regulation of rRNA synthesis. Consistent with such functional redundancy, the pocket protein p130 shares with $\mathrm{pRb}$ the ability to interact with UBF and repress Pol I transcription in vivo and in vitro (Ciarmatori et al. 2001).

Similar to $\mathrm{pRb}$ and $\mathrm{p} 130$, the tumor suppressor $\mathrm{p} 53$ has also been shown to repress Pol I transcription in vivo and in vitro. Wild-type, but not mutant, p53 can suppress Pol I transcription in cotransfection experiments, and p53deficient cells display increased pre-rRNA levels (Budde and Grummt 1999; Zhai and Comai 2000). p53 interacts with two subunits of SL1, TBP and $\mathrm{TAF}_{\mathrm{I}} 110$, which, in turn, impairs initiation complex formation. These results reveal a novel mechanism by which the tumor suppressors $\mathrm{pRb}$ and $\mathrm{p} 53$ inhibit cell proliferation, namely, by direct inhibition of cellular rRNA synthesis. Given that many tumor cells harbor mutations that affect both $\mathrm{pRb}$ and $\mathrm{p} 53$, the combined effect of both mutations may have an added impact on Pol I activity and tumor progression.

\section{Conclusions and perspectives}

In this review, I have summarized our present knowledge of the highly coordinated networks that regulate rRNA synthesis, and hence ribosome production, in response to external signals. Although the emerging picture of transcriptional regulation is one of unanticipated variety and complexity, we are beginning to understand the function of individual components of the Pol I transcription apparatus, the pathways that link rDNA transcription to cell growth, and the role of epigenetic mechanisms that establish the active and inactive state of ribosomal RNA genes. We shall soon be able to unravel the multiple pathways the cell uses to transfer extracellular signals into the nucleolus and modulate the activity of the Pol I transcription machinery. We need to understand the functional consequences of modifications of individual transcription factors as well as some more perplexing aspects of rDNA transcriptional regulation, such as the dynamics of assembly of different proteins into regulatory complexes. Knowing this is also of clinical importance, as the regulation of rRNA synthesis is abrogated in cancer cells, and will be essential for the discovery of novel therapeutic agents that target rDNA transcription regulators. Inactivating mutations in tumor suppressors and up-regulation of protein kinases that control rDNA transcription correlate with elevated pre-rRNA levels in transformed cells. Overexpression of rRNA, in turn, could lead to excess protein synthesis and thus could be an initiating step in tumorigenesis. The comparative application of candidate-gene and proteomics approaches should uncover key pathways that are deregulated in cancer cells. Although there are many questions yet to be answered, the elucidation of the signaling pathways that transmit information on the growth state of a cell population to the Pol I transcription apparatus represent challenging and rewarding subjects for future studies.

\section{Acknowledgments}

I apologize to those colleagues whose work I did not cite because of restriction of space. I acknowledge the numerous students and postdoctoral fellows who have contributed over the years to the results of my group. My special thanks go to one of the referees, who provided exceptionally thorough and insightful suggestions on the manuscript. Our work has been supported by the Deutsche Forschungsgemeinschaft, the European Union, the Fonds der Chemischen Industrie, and the BMBF.

\section{References}

Albert, A.-C., Denton, M., Kermekchiev, M., and Pikaard, C.S. 1999. Histone acetyltransferase and protein kinase activities copurify with a putative Xenopus RNA polymerase I holoenzyme self-sufficient for promoter-dependent transcription. Mol. Cell. Biol. 19: 796-806.

Aprikian, P., Moorefield, B., and Reeder, R.H. 2001. New model for the yeast RNA polymerase I transcription cycle. Mol. Cell. Biol. 21: 4847-4855.

Bazett-Jones, D.P., Leblanc, B., Herfort, M., and Moss, T. 1994. 
Short-range DNA looping by the Xenopus HMG-box transcription factor, xUBF. Science 264: 1134-1137.

Bodem, J., Dobreva, G., Hoffmann-Rohrer, U., Iben, S., Zentgraf, H., Delius, H., Vingron, M., and Grummt, I. 2000. TIF-IA, the factor mediating growth-dependent control of ribosomal RNA synthesis, is the mammalian homolog of yeast Rrn3p. EMBO Rep. 1: 171-175.

Bradsher, J., Auriol, J., Proietti de Santis, L., Iben, S., Vonesch, J.-L., Grummt, I., and Egly, J.-M. 2002. CSB is a component of RNA Pol I transcription. Mol. Cell 10: 819-829.

Buck, S.W., Sandmeier, J.J., and Smith, J.S. 2002. RNA polymerase I propagates unidirectional spreading of rDNA silent chromatin. Cell 222: 1003-1014.

Budde, A. and Grummt, I. 1999. p53 represses ribosomal gene transcription. Oncogene 18: 1119-1124.

Buttgereit, D., Pflugfelder, G., and Grummt, I. 1985. Growthdependent regulation of rRNA synthesis is mediated by a transcription initiation factor (TIF-IA). Nucleic Acids Res. 13: $8165-8180$.

Cavanaugh, A.H., Hempel, W.M., Taylor, L.J., Rogalsky, V., Todorov, G., and Rothblum, L.I. 1995. Activity of RNA polymerase I transcription factor UBF blocked by $\mathrm{Rb}$ gene product. Nature 374: 177-180.

Cavanaugh, A.H., Hirschler-Laszkiewicz, I., Hu, Q., Dundr, M., Smink, T., Misteli, T., and Rothblum, L.I. 2002. Rrn3 phosphorylation is a regulatory checkpoint for ribosome biogenesis. J. Biol. Chem. 277: 27423-27432.

Ciarmatori, S., Scott, P.H., Sutcliffe, J.E., McLees, A., Alzuherri, H.M., Dannenberg, J.-H., te Riele, H., Grummt, I., Voit, R., and White, R.J. 2001. Overlapping functions of the $\mathrm{pRb}$ family in the regulation of rRNA synthesis. Mol. Cell. Biol. 21: 5806-5814.

Clos, J., Buttgereit, D., and Grummt, I. 1986. A purified transcription factor (TIF-IB) binds to essential sequences of the mouse rDNA promoter. Proc. Natl. Acad. Sci. 83: 604-608.

Comai, L., Tanese, N., and Tjian, R. 1992. The TATA-binding protein and associated factors are integral components of the RNA polymerase I transcription factor, SL1. Cell 68: 965976.

Conconi, A., Widmer, R.M., Koller, T., and Sogo, J.M. 1989. Two different chromatin structures coexist in ribosomal RNA genes throughout the cell cycle. Cell 57: 753-761.

Copenhaver, G.P., Putnam, C.D., Denton, M.L., and Pikaard, C.S. 1994. The RNA polymerase I transcription factor UBF is a sequence-tolerant HMG-box protein that can recognize structured nucleic acids. Nucleic Acids Res. 22: 2651-2657.

Dennis, P.B., Jaeschke, A., Saitoh, M., Fowler, B., Kozma, S.C., and Thomas, G. 2001. Mammalian TOR: A homeostatic ATP sensor. Science 294: 1102-1105.

Dundr, M., Hoffmann-Rohrer, U., Hu, Q., Grummt, I., Rothblum, L.I., Phair, R.D., and Misteli, T. 2002. A kinetic framework for a mammalian RNA polymerase in vivo. Science 298: $1623-1626$.

Eberhard, D., Tora, L., Egly, J.M., and Grummt, I. 1993. A TBPcontaining multiprotein complex (TIF-IB) mediates transcription specificity of murine RNA polymerase I. Nucleic Acids Res. 21: 4180-4186.

Elliot, S.G. and McLaughlin, C.S. 1979. Regulation of RNA synthesis in yeast: Synthesis during the cell cycle. Mol. Gen. Genet. 169: 237-243.

Fath, S., Milkereit, P., Podtelejnikov, A.V., Bischler, N., Schultz, P., Bier, M., Mann, M., and Tschochner, H. 2000. Association of yeast RNA polymerase I with a nucleolar substructure active in rRNA synthesis and processing. I. Cell Biol. 149: 575-590.

Fath, S., Milkereit, P., Peyroche, G., Riva, M., Carles, C., and
Tschochner, H. 2001. Differential roles of phosphorylation in the formation of transcriptional active RNA polymerase I. Proc. Natl. Acad. Sci. 98: 14334-14339.

French, S.L., Osheim, Y.N., Cioci, F., Nomura, M., and Beyer, A.L. 2003. In exponentially growing Saccharomyces cerevisiae cells, rRNA synthesis is determined by the summed RNA polymerase I loading rate rather than by the number of active genes. Mol. Cell. Biol. 23: 1558-1568.

Gaal, T., Bartlett, M.S., Ross, W., Turnbough Jr., C.L., and Gourse, R.L. 1997. Transcription regulation by initiating NTP concentration: rRNA synthesis in bacteria. Science 278: 2092-2097.

Gotta, M., Strahl-Bolsinger, S., Renauld, H., Laroche, T., Kennedy, B.K., Grunstein, M., and Gasser, S.M. 1997. Localization of Sir2p: The nucleolus as a compartment for silent information regulators. EMBO J. 16: 3243-3255.

Gottlieb, S. and Esposito, R.E. 1989. A new role for a yeast transcriptional silencer gene, SIR2, in regulation of recombination in ribosomal DNA. Cell 56: 771-776.

Grummt, I. 1999. Regulation of mammalian ribosomal gene transcription by RNA polymerase I. Progr. Nucleic Acid Res. Mol. Biol. 62: 109-154.

Grummt, I. and Grummt, F. 1976. Control of nucleolar RNA synthesis by the intracellular pool sizes of ATP and GTP. Cell 7: 447-453.

Grummt, I. and Pikaard, C.S. 2003. Epigenetic control of ribosomal RNA gene transcription. Nat. Rev. Mol. Cell Biol. (in press).

Grummt, I., Smith, V.A., and Grummt, F. 1976. Amino acid starvation affects the initiation frequency of nucleolar RNA polymerase. Cell 7: 439-445.

Guarente, L. 2000. Sir2 links chromatin silencing, metabolism, and aging. Genes \& Dev. 14: 1021-1026.

Hanada, K., Song, C.Z., Yamamoto, K., Yano, K., Maeda, Y., Yamaguchi, K., and Muramatsu, M. 1996. RNA polymerase I associated factor 53 binds to the nucleolar transcription factor UBF and functions in specific rDNA transcription. EMBO J. 15: 2217-2226.

Hannan, R.D., Cavanaugh, A., Hempel, W.M., Moss, T., and Rothblum, L. 1999. Identification of a mammalian RNA polymerase I holoenzyme containing components of the DNA repair/replication system. Nucleic Acids Res. 27: 3720-3727.

Hannan, K.M., Kennedy, B.K., Cavanaugh, A.H., Hannan, R.D., Hirschler-Laszkiewicz, I., Jefferson, L.S., and Rothblum, L.I. 2000. RNA polymerase I transcription in confluent cells: Rb downregulates rDNA transcription during confluence-induced cell cycle arrest. Oncogene 19: 3487-3497.

Heix, J. and Grummt, I. 1995. Species specificity of transcription by RNA polymerase I. Curr. Opin. Genet. Dev. 5: 652656

Heix, J., Zomerdijk, J.C.B.M., Ravanpay, A., Tjian, R., and Grummt, I. 1997. Cloning of murine RNA polymerase Ispecific TAFs: Conserved interactions between the four subunits of the species-specific transcription factor TIF-IB/SL1. Proc. Natl. Acad. Sci. 94: 1733-1738.

Heix, J., Vente, A., Voit, R., Budde, A., Michaelidis, T.M., and Grummt, I. 1998. Mitotic silencing of human rRNA synthesis: Inactivation of the promoter selectivity factor SL1 by cdc2/cyclin B-mediated phosphorylation. EMBO J. 17: 73737381.

Hirschler-Laszkiewicz, I., Cavanaugh, A., Hu, Q., Catania, J., Avantaggiati, M.L., and Rothblum, L.I. 2001. The role of acetylation in rDNA transcription. Nucleic Acids Res. 29: 4114-4124.

Hisatake, K., Hasegawa, S., Takada, R., Nakatani, Y., Horikoshi, 
M., and Roeder, R.G. 1993. The p250 subunit of native TATA box-binding factor TFIID is the cell-cycle regulatory protein CCG1. Nature 362: 179-187.

Hoogstraten, D., Nigg, A.L., Heath, H., Mullenders, L.H., van Driel, R., Hoeijmakers, J.H., Vermeulen, W., and Houtsmuller, A.B. 2002. Rapid switching of TFIIH between RNA polymerase I and II transcription and DNA repair in vivo. Mol. Cell 10: 1163-1174.

Iben, S., Tschochner, H., Bier, M., Hoogstraten, D., Hozak, P., Egly, J.-M., and Grummt, I. 2002. TFIIH plays an essential role in polymerase I transcription. Cell 109: 297-306.

Imai, S., Armstrong, C.M., Kaeberlein, M., and Guarente, L. 2000. Transcriptional silencing and longevity protein Sir2 is an NAD-dependent histone deacetylase. Nature 403: 795800.

Jacob, S.T. 1995. Regulation of ribosomal gene transcription. Biochem. J. 306: 617-626.

Jantzen, H.M., Admon, A., Bell, S.P., and Tjian, R. 1990. Nucleolar transcription factor hUBF contains a DNA-binding motif with homology to HMG protein. Nature 344: 830 836.

Kaeberlein, M., McVey, M., and Guarente, L. 1999. The SIR2/ 3/4 complex and SIR2 alone promote longevity in Saccharomyces cerevisiae by two different mechanisms. Genes \& Dev. 13: 2570-2580.

Kermekchiev, M., Workman, J.L., and Pikaard, C.S. 1997. Nucleosome binding by the polymerase I transactivator upstream binding factor displaces linker histone H1. Mol. Cell. Biol. 17: 5833-5842.

Klein, J. and Grummt, I. 1999. Cell cycle-dependent regulation of RNA polymerase I transcription: The nucleolar transcription factor $\mathrm{UBF}$ is inactive in mitosis and early $\mathrm{G}_{1}$. Proc. Natl. Acad. Sci. 96: 6095-6101.

Kuhn, A. and Grummt, I. 1992. Dual role of the nucleolar transcription factor UBF: Trans-activator and antirepressor. Proc. Natl. Acad. Sci. 89: 7340-7344.

Kuhn, A., Stefanovsky, V., and Grummt, I. 1993. The nucleolar transcription activator UBF relieves $\mathrm{Ku}$ antigen-mediated repression of mouse ribosomal gene transcription. Nucleic Acids Res. 21: 2057-2063.

Kuhn, A., Vente, A., Dorée, M., and Grummt, I. 1998. Mitotic phosphorylation of the TBP-containing factor SL1 represses ribosomal gene transcription. J. Mol. Biol. 284: 1-5.

Learned, R.M., Cordes, S., and Tjian, R. 1985. Purification and characterization of a transcription factor that confers promoter specificity to human RNA poymerase I. Mol. Cell. Biol. 5: 1358-1369.

Lehmann, A.R. 2001. The xeroderma pigmentosum group D (XPD) gene: One gene, two functions, three diseases. Genes \& Dev. 15: 15-23.

Levine, A.J. 1997. P53, the cellular gatekeeper for growth and division. Cell 88: 323-331.

Lin, C.-Y., Tuan, J., Scalia, P., Bui, T., and Comai, L. 2002. The cell cycle regulatory factor TAF1 stimulates ribosomal DNA transcription by binding to the activator UBF. Curr. Biol. 12: 2142-2146.

Mahajan, P.B. 1994. Modulation of transcription of rRNA genes by rapamycin. Int. J. Immunopharmacol. 16: 711-721.

Mailand, N., Lukas, C., Kaiser, B.K., Jackson, P.K., Bartek, J., and Lukas, J. 2002. Deregulated human Cdc14A phosphatase disrupts centrosome separation and chromosome segregation. Nat. Cell Biol. 4: 317-322.

Marilley, M. and Pasero, P. 1996. Common DNA structural features exhibited by eukaryotic ribosomal gene promoters. Nucleic Acids Res. 24: 2204-2211.

Marilley, M., Radebaugh, C.A., Geiss, G.K., Laybourn, P.J., and
Paule, M.R. 2002. DNA structural variation affects complex formation and promoter melting in ribosomal RNA transcription. Mol. Genet. Genomics 267: 781-791.

Milkereit, P. and Tschochner, H. 1998. A specialized form of RNA polymerase I, essential for initiation and growth-dependent regulation of rRNA synthesis, is disrupted during transcription. EMBO J. 17: 3692-3703.

Miller, G., Panov, K.I., Friedrich, J.K., Trinkle-Mulcahy, L., Lamond, A.I., and Zomerdijk, J.C. 2001. hRRN3 is essential in the SL1-mediated recruitment of RNA polymerase I to RNA gene promoters. EMBO I. 20: 1373-1382.

Moorefield, B., Greene, E.A., and Reeder, R.H. 2000. RNA polymerase I transcription factor Rrn3 is functionally conserved between yeast and human. Proc. Natl. Acad. Sci. 97: 47244729.

Moss, T. and Stefanovsky, V.Y. 2002. At the center of eukaryotic life. Cell 109: 545-548.

Muth, V., Nadaud, S., Grummt, I., and Voit, R. 2001. Acetylation of $\mathrm{TAF}_{\mathrm{I}} 68$, a subunit of TIF-IB/SL1, activates RNA polymerase I transcription. EMBO J. 20: 1353-1362.

Nomura, M. 2001. Ribosomal RNA genes, RNA polymerases, nucleolar structures, and synthesis of rRNA in the yeast Saccharomyces cerevisiae. Cold Spring Harbor Symp. Quant. Biol. 66: 555-565.

O'Mahony, D.J., Xie, W.Q., Smith, S.D., Singer, H.A., and Rothblum, L.I. 1992. Differential phosphorylation and localization of the transcription factor UBF in vivo in response to serum deprivation. In vitro dephosphorylation of UBF reduces its transactivation properties. J. Biol. Chem. 267: 3538.

Panov, K.I., Friedrich, J.K., and Zomerdijk, J.C. 2001. A step subsequent to preinitiation complex assembly at the ribosomal RNA gene promoter is rate limiting for human RNA polymerase I-dependent transcription. Mol. Cell. Biol. 21: 2641-2649.

Pelletier, G., Stefanovsky, V.Y., Faubladier, M., Hirschler-Laszkiewicz, I., Savard, J., Rothblum, L.I., Cote, J., and Moss, T. 2000. Competitive recruitment of CBP and Rb-HDAC regulates UBF acetylation and ribosomal transcription. Mol. Cell 6: $1059-1066$.

Peyroche, G., Milkereit, P., Bischler, N., Tschochner, H., Schultz, P., Sentenac, A., Carles, C., and Riva, M. 2000. The recruitment of RNA polymerase I on rDNA is mediated by the interaction of the A43 subunit with Rrn3. EMBO J. 19: 573-5482.

Powers, T. and Walter, P. 1999. Regulation of the ribosome biogenesis by the rapamycin-sensitive TOR-signaling pathway in Saccharomyces cerevisiae. Mol. Biol. Cell 104: $987-$ 1000.

Proud, C.G. 2002. Regulation of mammalian translation factors by nutrients. Eur. J. Biochem. 269: 5338-5349.

Putnam, C.D., Copenhaver, G.P., Denton, M.L., and Pikaard, C.S. 1994. The RNA polymerase I transcription factor UBF requires its dimerization domain and HMG-box 1 to bend, wrap and positively supercoil enhancer DNA. Mol. Cell. Biol. 14: 6476-6488.

Reeder, R.H. 1999. Regulation of RNA polymerase I transcription in yeast and vertebrates. Prog. Nucleic Acid Res. Mol. Biol. 62: 293-327.

Ruppert, S., Wang, E.H., and Tjian, R. 1993. Cloning and expression of human $\mathrm{TAF}_{\mathrm{II}} 250$ : A TBP-associated factor implicated in cell-cycle regulation. Nature 362: 175-179.

Saez-Vasquez, J. and Pikaard, C.S. 1997. Extensive purification of a putative RNA polymerase I holoenzyme from plants that accurately initiates rRNA gene transcription in vitro. Proc. Natl. Acad. Sci. 94: 11869-11874. 
Schnapp, A. and Grummt, I. 1991. Transcription complex formation at the mouse rDNA promoter involves the stepwise association of four transcription factors and RNA polymerase I. J. Biol. Chem. 266: 24588-24595.

Schnapp, A., Pfleiderer, C., Rosenbauer, H., and Grummt, I. 1990. A growth-dependent transcription initiation factor (TIF-IA) interacting with RNA polymerase I regulates mouse ribosomal RNA synthesis. EMBO J. 9: 2857-2863.

Schnapp, A., Schnapp, G., Erny, B., and Grummt, I. 1993. Function of the growth-regulated transcription initiation factor TIF-IA in initiation complex formation at the murine ribosomal gene promoter. Mol. Cell. Biol. 13: 6723-6732.

Schneider, D.A., Gaal, T., and Gourse, R.L. 2002. NTP-sensing by rRNA promoters in Escherichia coli is direct. Proc. Natl. Acad. Sci. 99: 8602-8607.

Seither, P., Zatsepina, P., Hoffmann, M., and Grummt, I. 1997. Constitutive and strong association of PAF53 with RNA polymerase I. Chromosoma 106: 216-225.

Seither, P., Iben, S., and Grummt, I. 1998. Mammalian RNA polymerase I exists as a holoenzyme with associated basal transcription factors. J. Mol. Biol. 275: 43-53.

Seither, P., Iben, S., Thiry, M., and Grummt, I. 2001. PAF67, a novel protein that is associated with the initiation-competent form of RNA polymerase I. Biol. Chem. 382: 11631170.

Shou, W., Seol, J.H., Shevchenko, A., Baskerville, C., Moazed, D., Chen, Z.W., Jang, J., Shevchenko, A., Charbonneau, H., and Deshaies, R.J. 1999. Exit from mitosis is triggered by Tem1-dependent release of the protein phosphatase Cdc14 from nucleolar RENT complex. Cell 97: 233-244.

Shou, W., Sakamoto, K.M., Keener, J., Morimoto, K.W., Traverso, E.E., Azzam, R., Hoppe, G.J., Feldman, R.M.R., DeModena, J., Moazed, D., et al. 2001. Net1 stimulates RNA polymerase I transcription and regulates nucleolar structure independently of controlling mitotic exit. Mol. Cell 8: 4555.

Sirri, V., Roussel, P., and Hernandez-Verdun, D. 2000. In vivo release of mitotic silencing of ribosomal gene transcription does not give rise to precursor ribosomal RNA processing. I. Cell Biol. 148: 259-270.

Sirri, V., Hernandez-Verdun, D., and Roussel, P. 2002. Cyclindependent kinases govern formation and maintenance of the nucleolus. J. Cell Biol. 156: 969-981.

Tower, J. and Sollner-Webb, B. 1987. Transcription of mouse rDNA is regulated by an activated subform of RNA polymerase I. Cell 50: 873-883.

Tuan, J.C., Zhai, W., and Comai, L. 1999. Recruitment of TATA-binding protein-TAFI complex SL1 to the human ribosomal DNA promoter is mediated by the carboxy-terminal activation domain of upstream binding factor (UBF) and is regulated by UBF phosphorylation. Mol. Cell. Biol. 19: 2872-2879.

Voit, R. and Grummt, I. 2001. Phosphorylation of UBF at serine 388 is required for interaction with RNA polymerase I and activation of rDNA transcription. Proc. Natl. Acad. Sci. 98: 13631-13636.

Voit, R., Schnapp, A., Kuhn, A., Rosenbauer, H., Hirschmann, P., Stunnenberg, H.G., and Grummt, I. 1992. The nucleolar transcription factor mUBF is phosphorylated by casein kinase II in the C-terminal hyperacidic tail which is essential for transactivation. EMBO J. 11: 2211-2218.

Voit, R., Kuhn, A., Sander, E.E., and Grummt, I. 1995. Activation of mammalian ribosomal gene transcription requires phosphorylation of the nucleolar transcription factor UBF. Nucleic Acids Res. 23: 2593-2599.

Voit, R., Schäfer, K., and Grummt, I. 1997. Mechanism of re- pression of RNA polymerase I transcription by the retinoblastoma protein. Mol. Cell. Biol. 17: 4230-4237.

Voit, R., Hoffmann, M., and Grummt, I. 1999. Phosphorylation by $\mathrm{G}_{1}$-specific cdk-cyclin complexes activates the nucleolar transcription factor UBF. EMBO J. 18: 1891-1899.

Vu, L., Lee, B.-S., Josaitis, C.A., and Nomura, M. 1999. RNA polymerase switch in transcription of yeast rDNA: Role of transcription factor UAF (upstream activating factor) in silencing rDNA transcription by RNA polymerase II. Proc. Natl. Acad. Sci. 96: 4390-4395.

Walker, J.E., Saraste, M., Runswick, M.J., and Gay, N.J. 1982. Distantly related sequences in the $\alpha$ - and $\beta$-subunits of ATP synthase, myosin, kinases and other ATP-requiring enzymes and a common nucleotide binding fold. EMBO J. 1: 945-951.

Wang, L., Gout, I., and Proud, C.G. 2001. Cross-talk between the ERK and p70 S6 kinase (S6K) signaling pathways. MEKdependent activation of S6K2 in cardiomyocytes. I. Biol. Chem. 276: 32670-32677.

Warner, J.R. 1999. The economics of ribosome biosynthesis in yeast. Trends Biochem. Sci. 24: 437-440.

Yamamoto, R.T., Nogi, Y., Dodd, J.A., and Nomura, M. 1996. RRN3 gene of Saccharomyces cerevisiae encodes an essential RNA polymerase I transcription factor which interacts with the polymerase independently of DNA template. EMBO J. 15: 3964-3973.

Yasuda, H., Kamijo, M., Honda, R., Nakamura, M., Hanaoka, F., and Ohba, Y. 1991. A point mutation in C-terminal region of cdc2 kinase causes G2-phase arrest in a mouse temperaturesensitive FM3A cell mutant. Cell Struct. Funct. 16: 105-112.

Yuan, X., Zhao. J., Zentgraf, H., Hoffmann-Rohrer, U., and Grummt, I. 2002. Multiple interactions between RNA polymerase I, TIF-IA and $\mathrm{TAF}_{\mathrm{I}}$ subunits regulate preinitiation complex assembly at the ribosomal gene promoter. EMBO Rep. 3: 1082-1087.

Zaragoza, D., Ghavidel, A., Heitman, J., and Schultz, M.C. 1998. Rapamycin induces the G0 program of transcriptional repression in yeast by interfering with the TOR signaling pathway. Mol. Cell. Biol. 18: 4463-4470.

Zhai, W. and Comai, L. 2000. Repression of RNA polymerase I transcription by the tumor suppressor p53. Mol. Cell. Biol. 20: 5930-5938.

Zhao, J., Yuan, Y., Frödin, M., and Grummt, I. 2003. The activity of TIF-IA, a basal RNA polymerase I transcription factor, is regulated by MAP kinase-mediated signaling. Mol. Cell 11: 405-413. 


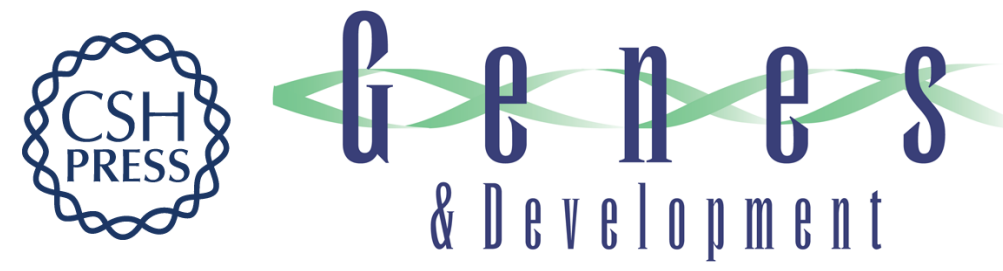

\section{Life on a planet of its own: regulation of RNA polymerase I transcription in the nucleolus}

Ingrid Grummt

Genes Dev. 2003, 17:

Access the most recent version at doi:10.1101/gad.1098503R

References This article cites 98 articles, 43 of which can be accessed free at: http://genesdev.cshlp.org/content/17/14/1691.full.html\#ref-list-1

License

Email Alerting

Receive free email alerts when new articles cite this article - sign up in the box at the top Service right corner of the article or click here.

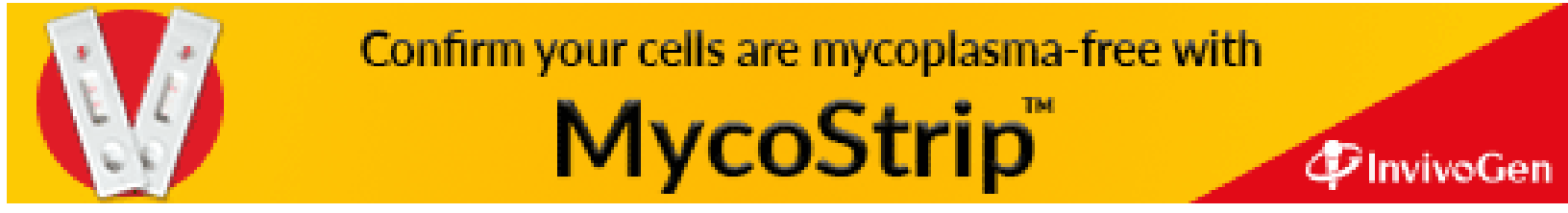

